\title{
On magnetospheric electron impact ionisation and dynamics in Titan's ram-side and polar ionosphere - a Cassini case study
}

\author{
K. Agren ${ }^{1}$, J.-E. Wahlund ${ }^{1}$, R. Modolo ${ }^{1}$, D. Lummerzheim ${ }^{2}$, M. Galand ${ }^{3}$, I. Müller-Wodarg ${ }^{3}$, P. Canu ${ }^{4}$, W. S. Kurth ${ }^{5}$, \\ T. E. Cravens ${ }^{6}$, R. V. Yelle ${ }^{7}$, J. H. Waite Jr. ${ }^{8}$, A. J. Coates ${ }^{9}$, G. R. Lewis ${ }^{9}$, D. T. Young ${ }^{10}$, C. Bertucci ${ }^{3}$, and \\ M. K. Dougherty ${ }^{3}$ \\ ${ }^{1}$ Swedish Institute of Space Physics, Box 537, 75121 Uppsala, Sweden \\ ${ }^{2}$ Geophysical Institute, University of Alaska, Fairbanks, AK 99775, USA \\ ${ }^{3}$ Space and Atmospheric Physics Group, Department of Physics, Imperial College London, London SW7 2BW, UK \\ ${ }^{4}$ Centre d' Etude des Environnements Terrestre et Planétaires/CNRS/Institut Pierre Simon Laplace, 78140 \\ Vélizy-Villacoublay, France \\ ${ }^{5}$ Department of Physics and Astronomy, University of Iowa, Iowa City, IA 52242, USA \\ ${ }^{6}$ Department of Physics and Astronomy, University of Kansas, Lawrence, KS 66045, USA \\ ${ }^{7}$ Lunar and Planetary Laboratory, University of Arizona, Tucson, AZ 85721, USA \\ ${ }^{8}$ Department of Atmospheric, Oceanic and Space Sciences, University of Michigan, Ann Arbor, MI 48109, USA \\ ${ }^{9}$ Mullard Space Science Laboratory, University College London, Holmbury St. Mary, Dorking, Surrey RH5 6NT, UK \\ ${ }^{10}$ Southwest Research Institute, San Antonio, TX 78238, USA
}

Received: 1 November 2006 - Revised: 5 November 2007 - Accepted: 14 November 2007 - Published: 29 November 2007

\begin{abstract}
We present data from the sixth Cassini flyby of Ti$\tan$ (T5), showing that the magnetosphere of Saturn strongly interacts with the moon's ionosphere and exo-ionosphere. A simple electron ionisation model provides a reasonable agreement with the altitude structure of the ionosphere. Furthermore, we suggest that the dense and cold exo-ionosphere (from the exobase at $1430 \mathrm{~km}$ and outward to several Titan radii from the surface) can be explained by magnetospheric forcing and other transport processes whereas exospheric ionisation by impacting low energy electrons seems to play a minor role.
\end{abstract}

Keywords. Ionosphere (Planetary ionospheres; Plasma temperature and density) - Magnetospheric physics (Magnetosphere-ionosphere interactions)

\section{Introduction}

Titan is the largest satellite of Saturn and features a dense atmosphere, mainly composed of molecular nitrogen and methane (Niemann et al., 2005). Measurements by the Cassini Ion and Neutral Mass Spectrometer (INMS) have also showed the existence of molecular hydrogen, argon and a host of stable carbon-nitrile compounds (Waite et al., 2005).

The first evidence for an ionosphere of Titan was provided by the radio occultation experiment on board Voyager 1 (Bird

Correspondence to: K. Ågren

(agren@irfu.se) et al., 1997) and since then a wide range of ionospheric models have been developed (e.g., Cravens et al., 2006; Vuitton et al., 2006; Molina-Cuberos, 2001; Banaszkiewicz et al., 2000; Galand et al., 1999; Keller et al., 1998; Ip, 1990). After Cassini reached Titan in late 2004 our knowledge of the ionosphere has increased even more. The first in-situ measurements of the ionosphere were made by Cassini during the Ta flyby in October 2004 (Wahlund et al., 2005).

Titan orbits Saturn at a distance of $20.3 \mathrm{R}_{\mathrm{S}}$. Usually the moon is inside Saturn's outer and nearly co-rotating magnetosphere. Regardless of the origin of the external magnetic field and plasma flow (magnetosheath or upstream solar wind) this interaction creates an induced magnetosphere around Titan (Ness et al., 1982; Backes et al., 2005) where various processes erode the ionosphere (Gurnett et al., 1982; Wahlund et al., 2005). The magnetospheric plasma flow of energetic particles also ionise the upper part of Titan's atmosphere. This phenomenon together with ionisation by solar ultraviolet (UV) radiation and charge-exchange with the flowing external plasma are considered to be the main ionisation sources of the ionosphere of Titan (Galand et al., 2006; Cravens et al., 2005; Wahlund et al., 2005). The ionisation is a major driver for the complex organic chemistry in the moon's atmosphere. Measurements by INMS from the sixth flyby (T5) show that intricate ion molecule chemistry indeed is operating on the nightside of Titan (Cravens et al., 2006; Vuitton et al., 2006).

Here we present observations mostly from the Radio and Plasma Wave Science (RPWS) instruments (Gurnett et al., 2004) during T5. Of these, particularly Langmuir Probe (LP)

Published by Copernicus Publications on behalf of the European Geosciences Union. 
T5 Flyby Geometry

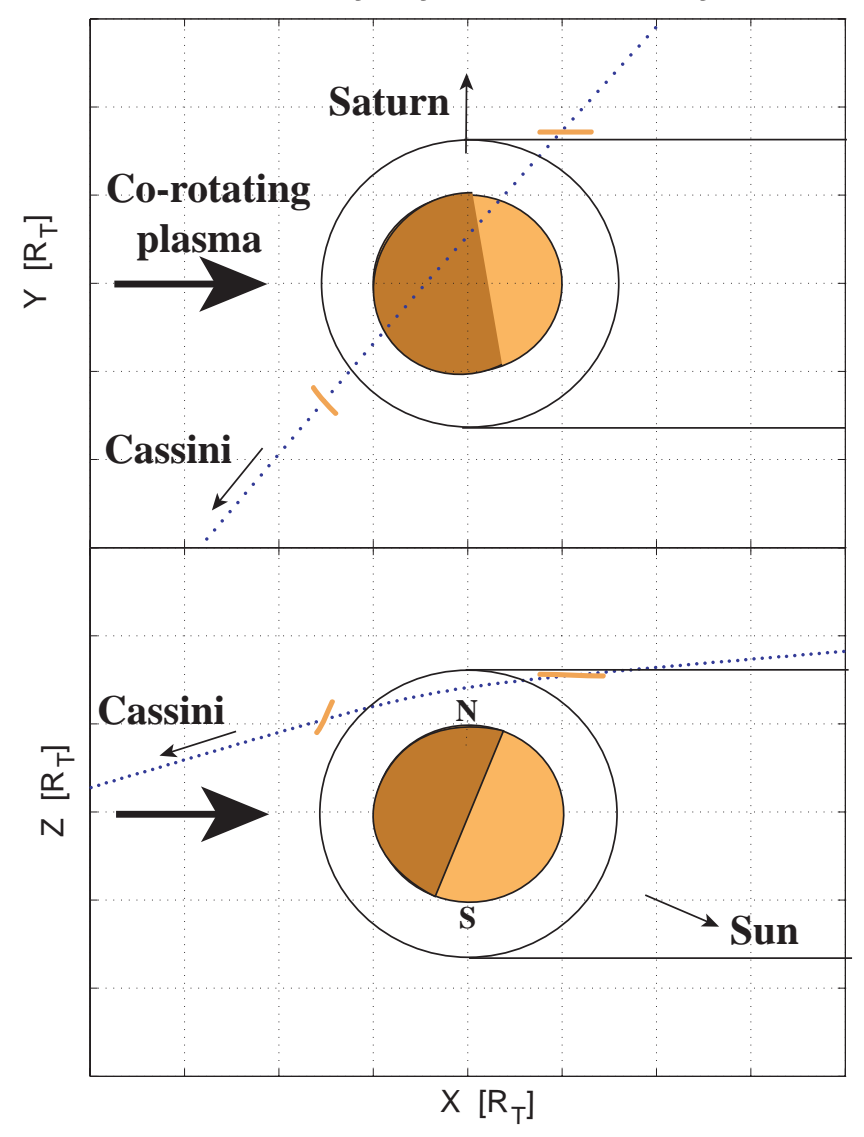

Fig. 1. Geometry of Cassini's Titan T5 Flyby, 16 April, 2005, with the spacecraft trajectory. Saturn ecliptic coordinates ( $X$ in corotation direction, $Y$ is toward Saturn, $Z$ is Saturn north). Each blue point represents one minute of flight. The circle around Ti$\tan$ represents the exobase at $1430 \mathrm{~km}$. The RPWS detected cold plasma of ionospheric origin out to heights about $2200 \mathrm{~km}$ inbound and $2500 \mathrm{~km}$ outbound (orange line-marks).

data is treated. This flyby offered favourable conditions to study the magnetospheric interaction with the polar and ramside ionosphere of Titan during nightside conditions (in absence of solar EUV ionisation). We concentrate on the cold plasma characteristics of this flyby. By using a neutral atmospheric model, constructed partly from INMS observations, and an electron transport code together with a simplified ionmolecule chemistry scheme, we were able to calculate a set of ionospheric profiles based on the observed CAPS/ELS magnetospheric incident electron distribution. These profiles were compared with RPWS ionospheric observations. By doing so we could reproduce the magnetospheric interaction on Titan's atmosphere.

\section{T5 flyby geometry}

The T5 flyby occurred on 16 April 2005. The Cassini spacecraft passed the nightside of Titan during the outbound leg and part of the inbound (see Fig. 1). There was therefore a possibility to enter the ram-side ionospheric pick-up region on the outbound leg, as it occurred on the anti-Saturn direction (see e.g. Tb inbound characteristics in Wahlund et al., 2005). The closest approach (C/A) occurred at an altitude of $1027 \mathrm{~km}$ at $19: 12 \mathrm{UT}$ over the north pole $\left(74^{\circ}\right)$ of Titan. T5 was a rather deep pass making it possible to study ionospheric structure in detail.

\section{RPWS observations during T5}

\subsection{Measurement principles}

The electron number density $\left(n_{\mathrm{e}}\right)$ can be estimated by numerous methods with several instruments on board Cassini. The RPWS investigation employs at least three different methods for this purpose, of which two will be described here. The third method, the sounder, was not operative during T5.

One method makes use of the upper hybrid emission line, which peaks in electric spectra at the frequency $f_{\mathrm{UH}} \approx \sqrt{f_{\mathrm{ge}}^{2}+f_{\mathrm{pe}}^{2}}$, where $f_{\mathrm{ge}}$ is the electron gyro-frequency and $f_{\mathrm{pe}}$ is the electron plasma frequency. Knowing the magnetic field strength, the electron gyro-frequency can be calculated, and the electron density can be derived from the electron plasma frequency. Near Titan the field is so weak that it is essentially the plasma frequency that is measured. This method of estimating the plasma density is used later on (see Fig. 4).

Another method makes use of the fact that the LP sensor samples the total electron number density surrounding the spacecraft. This can be carried out in several ways. From the parameter results of a two-electron and one drifting ion component Orbit Motion Limited (OML) theory (Mott-Smith and Langmuir, 1926) fit to the LP Voltage sweeps ( $\pm 4 \mathrm{~V}$ during T5) it is possible to estimate a number of cold plasma parameters. Among them are the electron number density and temperature $\left(T_{\mathrm{e}}\right)$ as well as the spacecraft potential $\left(U_{\mathrm{SC}}\right)$, but in most circumstances it is also possible to obtain values for the average ion mass $\left(m_{\mathrm{i}}\right)$, ion ram velocity $\left(v_{\mathrm{i}}\right)$, ion density $\left(n_{\mathrm{i}}\right)$, ion temperature $\left(T_{\mathrm{i}}\right)$, and solar UV intensity (e.g., Fahleson et al., 1974). LP sweeps were sampled each $24 \mathrm{~s}$ during the T5 flyby. An example of a voltage sweep with a superposed OML fit is shown in Fig. 2.

The LP also measures the current at a fixed bias voltage (+4 V during T5) at 20 samples/s, which is proportional to $\sqrt{T_{\mathrm{e}}} n_{\mathrm{e}}\left(1+\frac{1}{T_{\mathrm{e}}}\left(U_{\mathrm{SC}}+U_{\text {bias }}\right)\right)$. We can use the electron temperature and spacecraft potential estimates from the lower temporal resolution sweeps and assume $T_{\mathrm{e}} \approx$ constant and $U_{\mathrm{SC}} \approx$ constant between sweeps to derive $n_{\mathrm{e}}$ with a resolution of $20 \mathrm{~Hz}$. The bias potential $U_{\text {bias }} \approx+4 \mathrm{~V}$ is an instrument 
setting. This method works well as long as $U_{\mathrm{SC}}>-U_{\text {bias. }}$. If $U_{\mathrm{SC}}<-U_{\text {bias }}$ the ion/photo-electron current is sampled instead, which is harder to correct for. The $20 \mathrm{~Hz}$ density shown in Fig. 3 (panel 2) in region 3 (outbound) shows variations which are not in agreement with the upper hybrid derived density and that is most probably due to this error source.

Yet another method to estimate $n_{\mathrm{e}}$ originates from the fact that the LP essentially measures the photoelectron cloud around the spacecraft when situated in the outer magnetosphere of Saturn. There exists a relationship between the ambient magnetospheric density, the spacecraft potential and attitude versus the Sun, and the density of this photoelectron cloud around the spacecraft from which one can derive the magnetospheric electron density. Although more uncertain, we have used it for the magnetospheric upstream/downstream densities.

\subsection{General characteristics during the flyby}

The cold plasma can be divided into three different populations (time periods) based on the characteristics as inferred from the LP and upper hybrid emissions (Fig. 3, panel 2). Each population is discussed in detail in the following sections.

The LP current for negative bias voltage (Fig. 3, panel 5) is sensitive to the solar EUV photoelectron emission from the probe $(\approx-0.7 \mathrm{nA}$ during $\mathrm{T} 5)$ as well as the more variable ion ram current from the surrounding plasma. In lowdensity plasma, as in region 1 , the absence of the nearly constant photocurrent indicates that the spacecraft is in darkness. In dense plasma a sudden decrease of $0.7 \mathrm{nA}$ without a corresponding change in density (compare panel 2) indicates a transition into eclipse. In this way we identify the spacecraft eclipse region to be between 19:09-19:25 UT.

\subsection{Region 1 - Upstream environment}

The magnetospheric plasma of Saturn dominates region 1. Densities are estimated to be $\approx 0.1 \mathrm{~cm}^{-3}$ (e.g. near 18:50 UT), but errors could be as large as a factor of two. For this region CAPS/ELS was providing more accurate measurements than RPWS, but gives values very similar to the ones from RPWS. The shown electron temperatures (panel 3) are most probably due to the photoelectron cloud around the spacecraft and certainly not true magnetospheric temperatures.

The dc current to the LP for negative bias voltage is proportional to the ram flux of ions $\left(n_{\mathrm{i}} v_{\mathrm{i}}\right)$. By using the condition that the plasma must be electrically neutral, $n_{\mathrm{e}}=n_{\mathrm{i}}$, it is possible to estimate the ion ram speed $\left(v_{\mathrm{i}}\right)$, which is displayed in panel 6 (blue dots) of Fig. 3. This estimate is dependent on a correction for the EUV intensity and the associated photoelectron flux from the sensor.

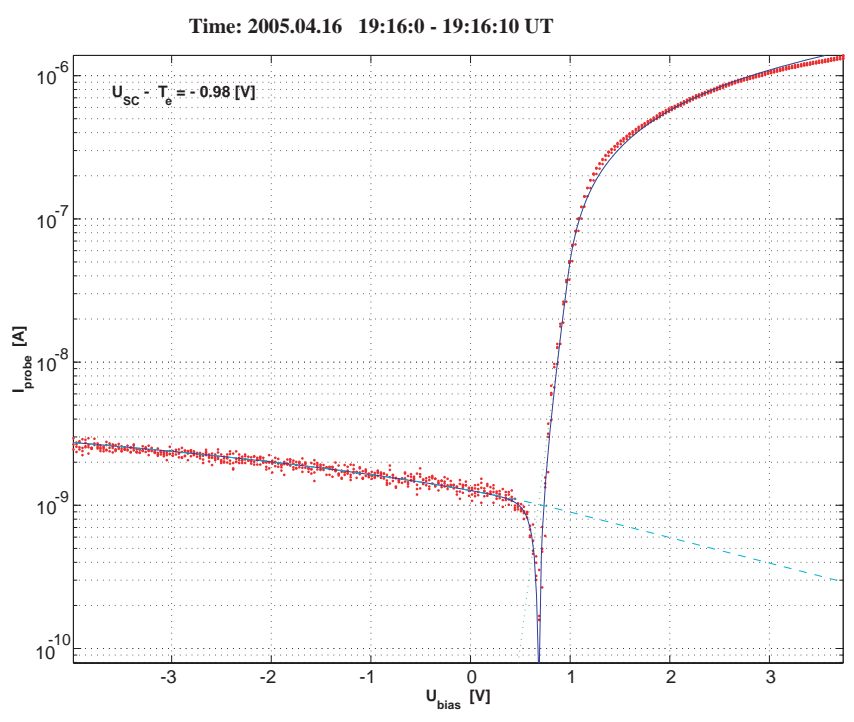

Fig. 2. The current-voltage characteristic (red dots) of a RPWS Langmuir Probe sweep sampled in the outbound part ionosphere of the T5 flyby. Superposed is an OML fit to the data, also indicating the electron and ion current contributions. Derived parameters are $v_{\mathrm{i}}=4 \mathrm{~km} / \mathrm{s}, m_{\mathrm{i}}=28, T_{\mathrm{e}}=0.08 \mathrm{eV}, n_{\mathrm{e}}=700 \mathrm{~cm}^{-3}$ and $U_{\mathrm{SC}}=-0.9 \mathrm{~V}$.

Estimations of plasma parameters are derived from the study of the current-voltage characteristic curve (Fig. 2), as presented in Sect. 3.1. For a negative bias potential $\left(U_{\text {bias }}<0 \mathrm{~V}\right)$ ions are sampled while almost all electrons are repelled, so the study of the current-voltage curve provides information mainly of the ion population. An independent estimate of the ion ram speed can be obtained from the slope of the current-voltage curve (with $U_{\text {bias }}<0$ ) by assuming values of the averaged ion mass $\left(m_{\mathrm{i}}\right)$. In Fig. 3 (panel 6 , red dots-line) the resulting ion ram speed values in the magnetosphere are shown for protons $(1 \mathrm{amu})$. The values become uncertain and underestimated due to the small voltage-current slope for large energies $(>100 \mathrm{eV})$. Using these methods, upstream ion speeds of $\sim 100 \mathrm{~km} / \mathrm{s}$ are inferred considering the possible error sources above.

\subsection{Region 2 - Ionosphere}

The ionosphere is the region beneath the ionopause where the thermal pressure dominates over the magnetic and dynamic pressures in the magnetosphere. During the T5 flyby it was characterised by large densities around $1000 \mathrm{~cm}^{-3}$ (Fig. 3, panel 2), low electron temperatures below $0.1 \mathrm{eV}$ (panel 3), a negative spacecraft potential near -0.9 to $-1 \mathrm{~V}$, and ion ram speeds close to the spacecraft speed. During T5 the magnetic pressure in the ionosphere $\left(B^{2} /\left(2 \mu_{0}\right) \approx 50-\right.$ $100 \mathrm{eV} / \mathrm{cm}^{-3}$ ) was, in fact, comparable to the thermal pressure of the ionosphere (compare with Fig. 5, panel 4). Even though plasma collisions with the neutral atmosphere 


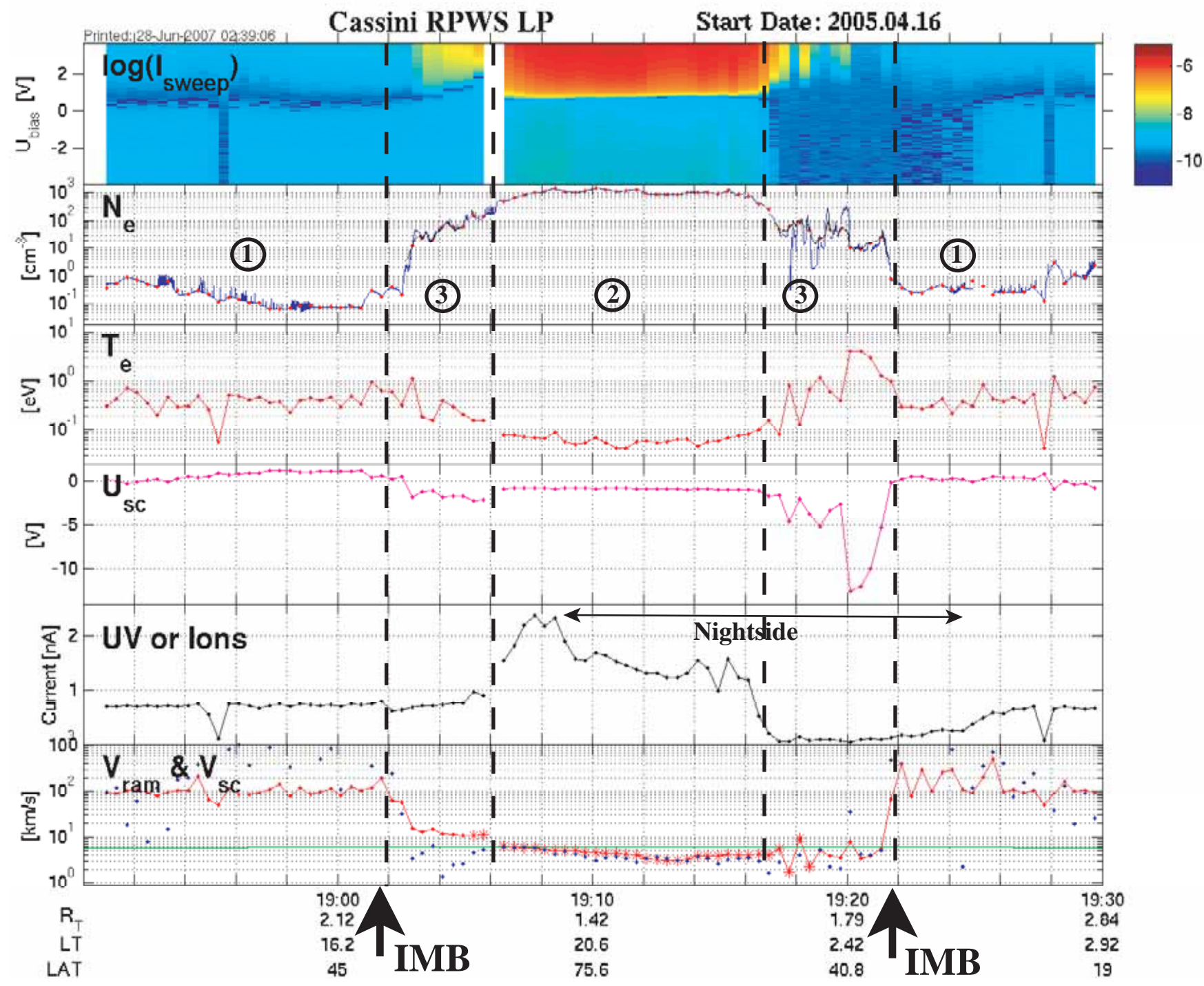

Fig. 3. Overview of the RPWS derived parameters for the T5 flyby. Parameters are calibrated LP sweep data (panel 1); $n_{\mathrm{e}}(\mathrm{panel} 2)$ from LP sweeps (red dots), LP $20 \mathrm{~Hz}$ (blue line) and $f_{\mathrm{UH}}$ derived density (black line) deduced from Fig. 4; $T_{\mathrm{e}}$ (panel 3) from LP sweeps (red dot-line); $U_{\mathrm{SC}}$ (panel 4) from LP sweeps; current for LP negative bias voltage (panel 5); and $v_{\mathrm{i}}$ (panel 6) from total ion current (blue dots) and slope for negative bias (red dot-line). The induced magnetospheric boundary (IMB) should be close to the outward edge of region 3 (exo-ionosphere). Region 1 is the upstream magnetosphere and region 2 the proper ionosphere. Derived electron temperatures in the magnetosphere (region 1 ) are most probably due to the spacecraft photoelectrons and are not representing the true magnetospheric electron temperatures. Shown with arrows is the approximate position of the induced magnetospheric boundary (IMB).

dominate, magnetospheric forcing should be able to affect the fine structure of the ionosphere within the measured region.

Inside the ionospheric region we adopted an average ion mass derived by the INMS instrument (Fig. 5, panel 3, blue line) (Cravens et al., 2006). This parameter is used in the calculation of the ion speed using the slope-method described above (Fig. 3, panel 5, red dots), which agrees well with the ion speeds using the other method (blue dots). A flow opposite the spacecraft ram direction of about $1-3 \mathrm{~km} / \mathrm{s}$ is sug- gested over this polar ionospheric pass.

The outbound ionospheric densities agree very well with INMS derived densities (Cravens et al., 2006). The flyby occurred over Titan's north dark hemisphere so basically the entire ionospheric pass occurred during nightside conditions (compare with Fig. 1). 


\subsection{Region 3 - Exo-ionosphere}

Upper hybrid derived electron densities were available in region 3 (Fig. 3, panel 2, black line, based on emissions like the outbound example in Fig. 4). On the inbound the $20 \mathrm{~Hz}$ LP densities were almost identical with the upper hybrid derived densities, and the electron temperature was rather stable and cold $(0.1-0.3 \mathrm{eV})$. Near 19:02:50 UT a sharp transition occurred in $n_{\mathrm{e}}$ (and $T_{\mathrm{e}}$ ) from magnetospheric values to about $20 \mathrm{~cm}^{-3}$, the densities stayed at a large level and increased exponentially with decreasing altitude to $200 \mathrm{~cm}^{-3}$ at 19:06 UT. The small scale-height $\left(H_{\mathrm{p}}\right)$ of $320 \mathrm{~km} \pm 50 \mathrm{~km}$ puts constraints on which physics operates here (compare with Fig. 5).

In this region the magnetic pressure $\left(100-200 \mathrm{eV} / \mathrm{cm}^{-3}\right)$ is larger than the thermal pressure $\left(\approx 20 \mathrm{eV} / \mathrm{cm}^{-3}\right)$, as can be seen in Fig. 5, panel 4. The production of plasma by magnetospheric impact ionisation (and/or solar EUV radiation when sunlit) of the exosphere can be large here. This region could therefore rightly be called an exo-ionosphere, even though the magnetospheric forcing controls a major part of the dynamics. Furthermore, the exobase is also the altitude where the ion gyro-period $(\approx 230 \mathrm{~s})$ becomes smaller than the average time between ion-molecule collisions, and therefore make ion-pickup easier in the exo-ionosphere.

The outbound ram-region is more structured than the inbound pole/tail-region. On the other hand, the average density varies as before between $200 \mathrm{~cm}^{-3}$ and a few $\mathrm{cm}^{-3}$, and the plasma scale height is similar to the inbound values $\left(H_{\mathrm{p}}=310 \pm 50 \mathrm{~km}\right)$. An electron temperature of up to a few $\mathrm{eV}$ indicates the presence of a local electron heating (energisation) source, possibly induced by an interaction with the magnetospheric flow. A dense and an electron-hot plasma is also consistent with the larger negative spacecraft potentials down to $-10 \mathrm{~V}$ observed on the outbound pass.

Even though RPWS ion ram speed values are associated with large errors between 19:17-19:22 UT, the region 3 ion speeds are consistent with a mass loading process due to the presence of the plasma produced by Titan. We can therefore indicate the approximate locations of the induced magnetospheric boundaries (IMB) (e.g., Vignes et al., 2000; Lundin and Barabash, 2004; Lundin et al., 2004; Bertucci et al., 2005) to be near the upper boundary of the exo-ionosphere. This boundary has been given many names, like the magnetic pileup boundary (MPB) or the mass loading boundary (MLB). In this region heavy ions from the ionosphere are accelerated (picked-up) downstream by the magnetospheric $\boldsymbol{v} \times \boldsymbol{B}$ induced electric field (around $1 \mathrm{mV} / \mathrm{m}$ ). At the same time the magnetospheric ion flow slows down because of the heavy loading of matter by the ionosphere. The exoionosphere is therefore also the region where cold (thermal) plasma, of mostly $\mathrm{C}_{2} \mathrm{H}_{5}^{+}$and $\mathrm{H}_{2} \mathrm{CN}^{+}$(Cravens et al., 2006), escapes to the surrounding space.

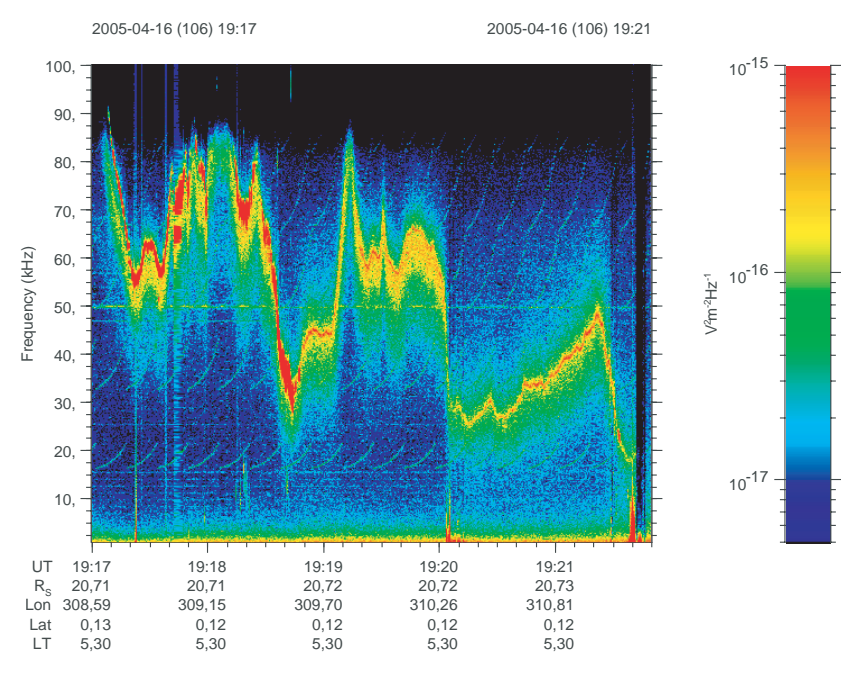

Fig. 4. RPWS electric field emissions from the outbound portion of the $\mathrm{T} 5$ flyby. The plasma line can be clearly identified.

\subsection{Range profiles}

Range profiles along the flyby track for $n_{\mathrm{e}}, T_{\mathrm{e}}, m_{\mathrm{i}}, P_{\mathrm{e}}, P_{\mathrm{B}}$ and the quality factor of the fit are presented in Fig. 5. The proper ionosphere reaches an altitude of about 1400$1500 \mathrm{~km}$, i.e., very close to the exobase near $1429 \mathrm{~km}$ (Waite et al., 2005). Above this altitude the rather dense $\left(>10 \mathrm{~cm}^{-3}\right)$ exo-ionosphere exists, which is produced by a combination of ionisation of the exosphere and various transport processes like ion pick-up and direct magnetospheric forcing $\left(B^{2} /\left(2 \mu_{0}\right)>n_{\mathrm{e}} k_{\mathrm{Boltz}} T_{\mathrm{e}}\right)$ of cold plasma (Wahlund et al., 2005). The cold dense exo-ionospheric plasma reaches up to a height of $2200 \mathrm{~km}$ (inbound) and $2500 \mathrm{~km}$ (outbound) from Titan's surface.

The LP sweep derived electron temperature (Fig. 5, panel 2) shows a rather steady gradient up to the exobase level, which continues on the inbound out to $2200 \mathrm{~km}$. The C/A temperature is about $0.06 \mathrm{eV}$. The outbound $T_{\mathrm{e}}$ profile is more complex above the exobase as discussed in Sect. 3.5, showing local electron energisation (heating).

The average ion mass inferred by the LP compares well with the INMS measurements (Fig. 5, panel 3, blue line). The discrepancies at the lowest altitudes (below $1100 \mathrm{~km}$ ) are not yet well understood, and are beyond the scope of this article. However, the good agreement above this altitude makes it possible to constrain the ion temperature, since a significant increase would increase the estimated ion speed to unreasonable values (compare $T_{\mathrm{i}}[\mathrm{eV}] \approx m_{\mathrm{i}} v_{\mathrm{i}}^{2} /(2 \mathrm{e})$ ). Below the exobase the ion temperature must be less than $0.8-2 \mathrm{eV}$. Above the exobase (inbound only) up to $1900 \mathrm{~km}$, the ion temperature must be below $2-5 \mathrm{eV}$. In the range $1900-2200 \mathrm{~km} T_{\mathrm{i}}<10-12 \mathrm{eV}$. The LP measurements therefore exclude the possibility of a hot ion corona dominated by atmospheric produced ions. 


\section{Cassini RPWS LP, Inbound(red), Outbound(black)}
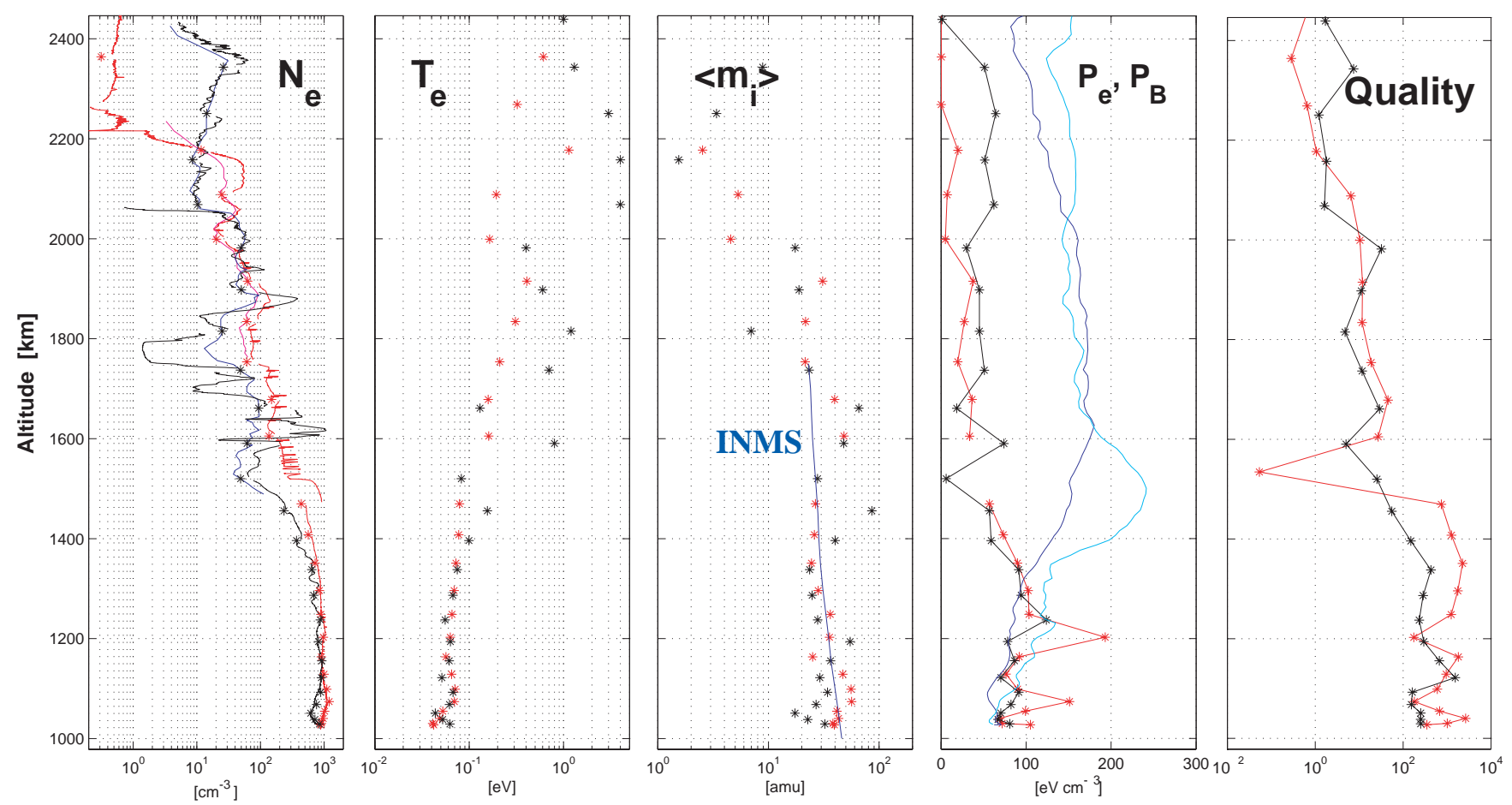

Fig. 5. Range profiles of RWPS derived parameters from the T5 flyby. The outbound (black) and inbound (red) values compare well on the average except for $T_{\mathrm{e}}$ at high altitudes (panel 2). In panel 1 the different curves are LP sweeps (stars), LP $20 \mathrm{~Hz}$ (black or red line) and $f_{\mathrm{UH}}$ derived densities (pink = inbound, blue = outbound). The INMS values for $m_{\mathrm{i}}$ from Cravens et al. (2006) are superposed (panel 3, blue line) on the LP derived $m_{\mathrm{i}}$. Panel 4 shows the thermal, $P_{\mathrm{e}}=n_{\mathrm{e}} k_{\mathrm{B}} T_{\mathrm{e}}$, (red $=$ inbound, black $=$ outbound $)$ and the magnetic, $P_{\mathrm{B}}=B^{2} /\left(2 \mu_{0}\right),($ blue $=$ inbound, cyan $=$ outbound) pressures. The quality factor is shown in panel 5 .

Comments on the influence of the thermal and the magnetic pressures (Fig. 5, panel 4) have already been included in Sects. 3.4 and 3.5 corresponding to the different regions: ionosphere and exo-ionosphere.

Estimations of the error bars for $n_{\mathrm{e}}$ and $T_{\mathrm{e}}$ are $10 \%$ and $20 \%$ respectively. As $m_{\mathrm{i}}$ is the last derived parameter from the LP analysis large variations can be found for this parameter. In order to have an estimation of the quality of the fit between the theoretical expressions and the observations we have plotted a quality factor (Fig. 5, panel 5). A higher quality factor means that there is an excellent agreement, whereas a lower factor indicates that there is a discrepancy between the theoretical and the measured current. Figure 5, panel 5, illustrates that the LP provides accurate estimations of the plasma parameters.

\section{Simplified ionospheric model with electron impact ionisation}

In order to interpret the data further we have developed an ionospheric model valid for T5 conditions. This is based on Rees' formula (1963) and a simplified version of Keller's chemistry scheme (Keller et al., 1998). For electron energies below $200 \mathrm{eV}$ an electron transport code is introduced (Lummerzheim, 1987). By using measurements of the neutral density (by INMS) and the incoming electron spectrum (by CAPS/ELS) we can derive estimated ion and electron densities for the T5 flyby. A more thorough description of the model and comparisons to data are given below.

\subsection{Neutral atmosphere model}

The ionosphere profile calculations presented here make use of a composite neutral atmosphere model that consists of several different inputs. The density profiles used are shown in Fig. 6. Molecular nitrogen, $\mathrm{N}_{2}$, is the main constituent of the atmosphere at low altitudes with methane, $\mathrm{CH}_{4}$, being the second most common. The molecular nitrogen and 


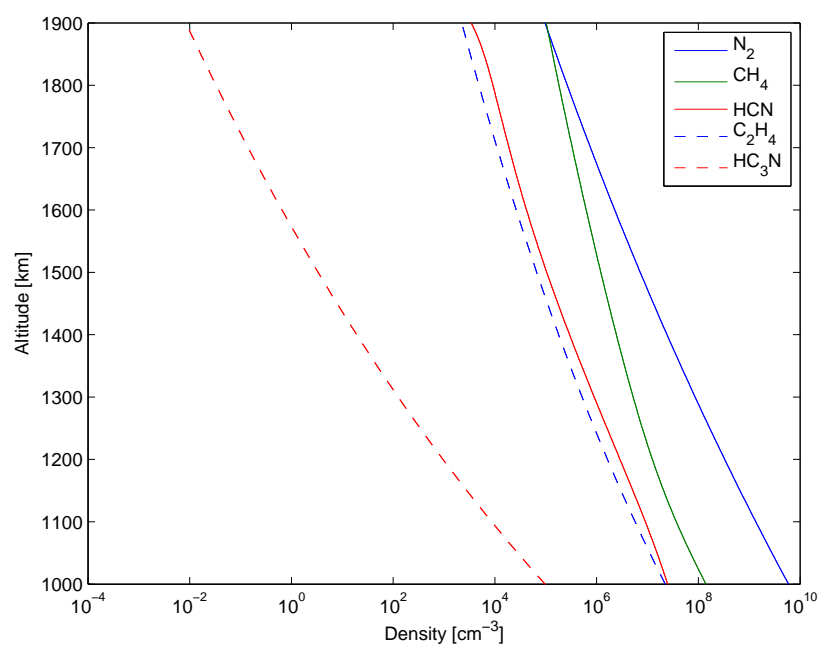

Fig. 6. Density profiles of the major and minor species on Titan used in calculations.

methane density profiles are consistent with measurements by the INMS during T5 (Yelle et al., 2006) and the densities of $\mathrm{C}_{2} \mathrm{H}_{4}$ and $\mathrm{HC}_{3} \mathrm{~N}$ are given by photochemical modelling based on Voyager data (Toublanc et al., 1995).

$\mathrm{HCN}$ is a minor gas in Titan's atmosphere and created as a by-product of ionospheric chemistry. However, the importance of $\mathrm{HCN}$ rotational cooling for the temperatures in Titan's thermosphere has been pointed out by Yelle (1991). Since HCN mixing ratios in the thermosphere are currently not well constrained by observations, we use a 1-D version of the General Circulation Model of Müller-Wodarg et al. (2003) to infer the vertical HCN profile used in this study. In this model, the vertical HCN structure is calculated considering solar EUV heating as the only external energy source. The model includes vertical molecular conduction as internal energy redistribution processes. HCN rotational cooling is calculated self-consistently, including radiative transfer. The model also calculates vertical molecular and eddy diffusion of all gases. Since HCN is formed in Titan's upper atmosphere, we include an empirical dayside $\mathrm{HCN}$ production rate in the model which peaks near $900 \mathrm{~km}$ altitude, as described by Müller-Wodarg et al. (2003), and set the rate to ensure that thermospheric temperatures match values inferred from the INMS observations by Yelle (2006). So, our HCN profiles are constrained by the thermal structure, rather than by ionospheric chemistry, in contrast to the approach by Vuitton et al. (2006).

\subsection{Ionosphere model}

Calculations have been made for various electron energies $(10 \mathrm{eV}<E<1000 \mathrm{eV})$ and their corresponding fluxes. The fluxes used are derived from ELS measurements, see Fig. 10. The magnetic field around Titan is shown to be very variable

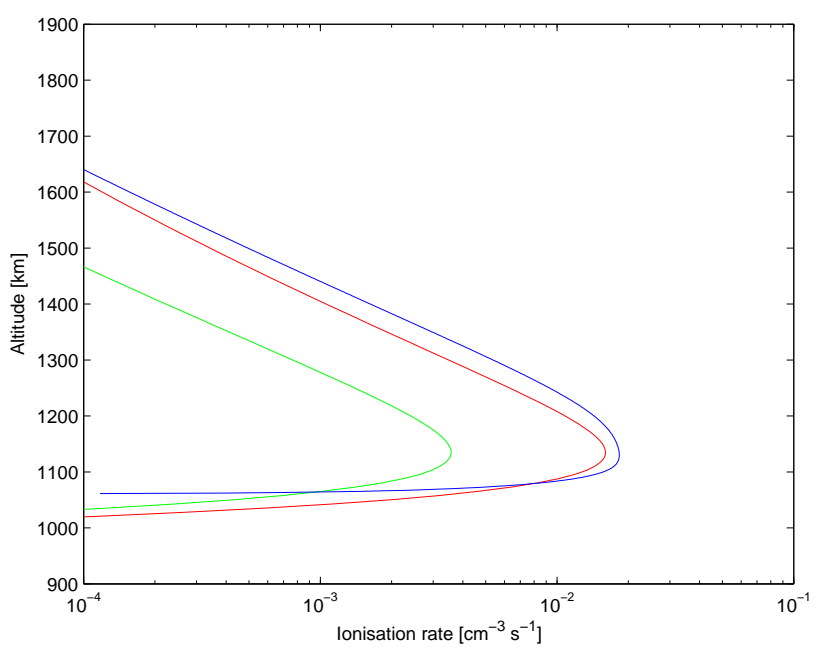

Fig. 7. Ionisation rates for $E=200 \mathrm{eV}$ and $F=1.3 \times 10^{5} \mathrm{~cm}^{-2} \mathrm{~s}^{-1}$ calculated by the electron transport code (red) and by using the Rees' formula (blue). Shown in green is the fraction that is due to ionisation of $\mathrm{CH}_{4}$.

and dynamic (Backes et al., 2005; Neubauer et al., 2006). We have not at this stage taken into account the geometry effect of the magnetic field.

For electron impact energies above $200 \mathrm{eV}$ we have calculated the ionisation rate height profiles for various electron energies and fluxes according to Rees (1963) and both unidirectional and isotropic beam distributions have been considered. Final results will be shown only for the isotropic case, which is a better approximation to what can be expected at Titan. For electron impact energies below $200 \mathrm{eV}$ we used an electron transport code. This is due to the fact that the effective range used in Rees (1963) is dependent on the assumption that the energy loss per electron-ion pair produced is constant. This breaks down for low energy incident electrons, for which additional collisions, such as excitation collisions, become more important than ionisation. In such a case, the average energy loss per electron-ion pair produced becomes larger.

The electron transport used for this calculation is based on the aurora model by Lummerzheim (1987) and Lummerzheim and Lilensten (1994). The model solves a steady state electron transport equation, which takes into account discrete energy loss, secondary electron production, and elastic collisions. In order to adapt the model to the Titan atmosphere, an $\mathrm{N}_{2}$-based neutral atmosphere was constructed, and the energy deposition and ionisation rate profiles were calculated as a function of column integrated density. This allows straight forward scaling to the altitude in the actual Titan atmosphere. Incident electron spectra were assumed to be isotropic with a Gaussian energy distribution where the half-width of the Gaussian was given by $10 \%$ of the peak 


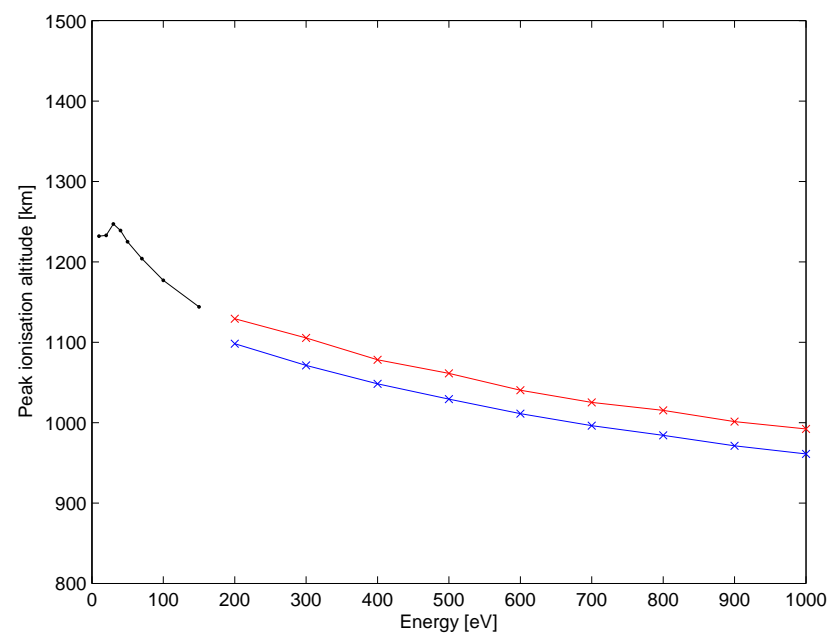

Fig. 8. Peak altitudes for the ionisation rates. Values corresponding to a unidirectional beam (blue), an isotropic distribution (red) and results from the electron transport code (black).

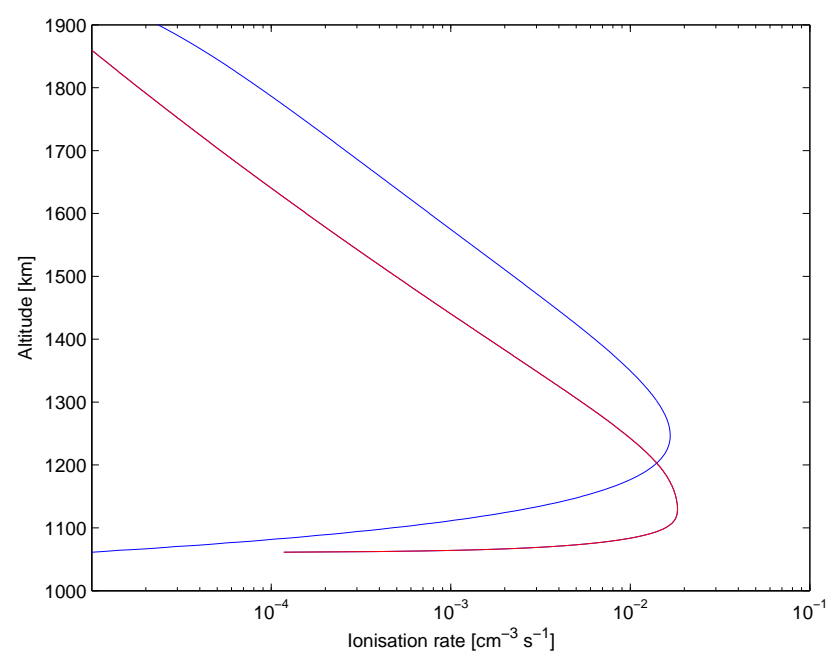

Fig. 9. Ion $\left(\mathrm{N}_{2}^{+}\right)$production rates (q) for $30 \mathrm{eV}$ (blue) and $200 \mathrm{eV}$ (red) impacting electron energies. Fluxes are $7.9 \times 10^{5} \mathrm{~cm}^{-2} \mathrm{~s}^{-1}$ and $1.3 \times 10^{5} \mathrm{~cm}^{-2} \mathrm{~s}^{-1}$ respectively. The rates for $30 \mathrm{eV}$ electrons are large at high altitudes, and $n_{\mathrm{e}} / q<2 \pi / \Omega_{\mathrm{i}}$ (an ion gyroperiod) in the exo-ionosphere.

energy. Model calculation were performed with peak energies varying from 10 to $150 \mathrm{eV}$.

As nitrogen is the dominant species in Titan's atmosphere, the total number density is taken to be the nitrogen number density. The same applies for the energy loss per ion formation, where we use the experimentally found value for $\mathrm{N}_{2}$ of $37 \mathrm{eV}$ (Rees, 1963). We validate this approach by comparing the ionisation rate we estimate assuming a pure nitrogen atmosphere with the rate given by the transport code assuming an atmosphere containing both nitrogen and methane (Ga-

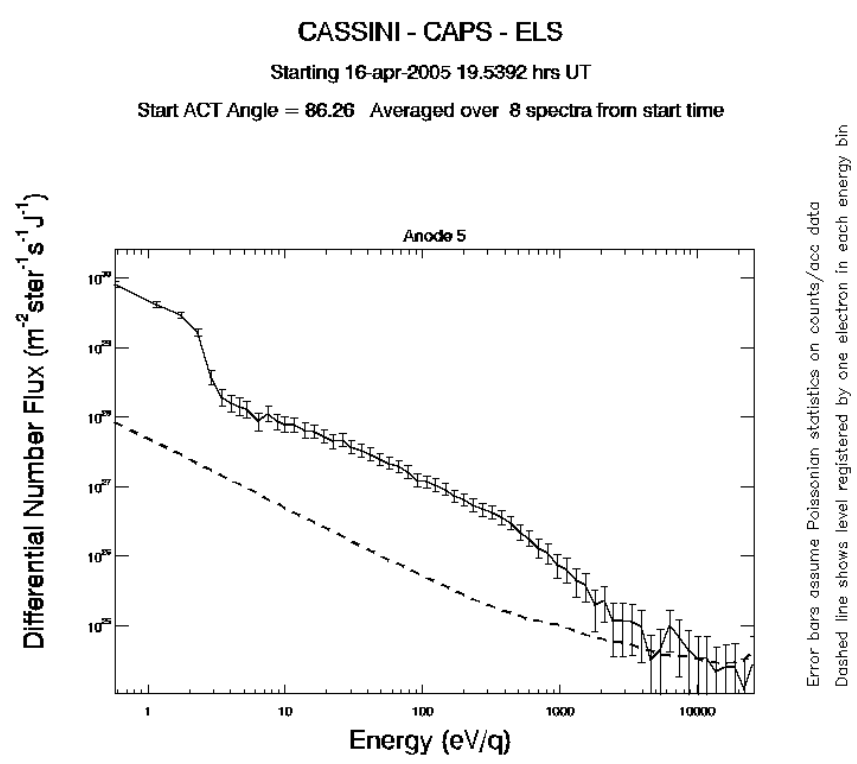

Fig. 10. CAPS/ELS differential electron fluxes in the magnetosphere. Data taken during the outbound trajectory. A broad energy electron population between a few $\mathrm{eV}$ and $2000 \mathrm{eV}$ is detected. The spacecraft photoelectrons are observed below $3 \mathrm{eV}$.

land et al., 2006), as illustrated in Fig. 7 for an energy of $200 \mathrm{eV}$. Such a comparison showing a good agreement between both rates also validates our choice to use the continuous slowing down approximation for energies above $200 \mathrm{eV}$.

Figure 8 shows peak ionisation altitudes as a function of electron energy for a pure $\mathrm{N}_{2}$ atmosphere. Values given for an isotropic distribution of the incoming electrons (red line) are compared with a unidirectional beam (blue line). Results from the electron transport code are shown in black, which are in agreement with Cravens et al. (2005). The transport code results complement very well the method by Rees (1963). Figure 9 shows the corresponding $\mathrm{N}_{2}$ production rates versus altitude for $30 \mathrm{eV}$ and $200 \mathrm{eV}$ incident electrons. For the electron fluxes we use values based on the observed CAPS/ELS magnetospheric incident electron distribution (Fig. 10).

The ion-molecule chemistry is adopted from a simplified version of Keller et al. (1998). Only the main reactions leading to the formation of $\mathrm{H}_{2} \mathrm{CN}^{+}$and $\mathrm{C}_{2} \mathrm{H}_{5}^{+}$have been included, but with the addition of recombination of $\mathrm{C}_{2} \mathrm{H}_{5}^{+}$. In this model, the main sequence starts with molecular nitrogen being ionised. The ionised nitrogen later reacts with methane and $\mathrm{HCN}$ to form $\mathrm{H}_{2} \mathrm{CN}^{+}$and $\mathrm{C}_{2} \mathrm{H}_{5}^{+}$. We have also modelled the formation of certain heavier ions, i.e. $\mathrm{C}_{3} \mathrm{H}_{2} \mathrm{~N}^{+}$and $\mathrm{C}_{5} \mathrm{H}_{5} \mathrm{~N}^{+}$. The recombination coefficient used for $\mathrm{H}_{2} \mathrm{CN}^{+}$, $\mathrm{C}_{2} \mathrm{H}_{5}^{+}$and $\mathrm{C}_{5} \mathrm{H}_{5} \mathrm{~N}^{+}$is $6.4 \times 10^{-7} \sqrt{300 / T_{\mathrm{e}}} \mathrm{cm}^{-3} \mathrm{~s}^{-1}$ (Keller et al., 1998). The electron temperature is taken from LP data and set to $700 \mathrm{~K}$ (See Fig. 5). Even with this simplified model we can obtain useful comparisons to data, as shown below. 


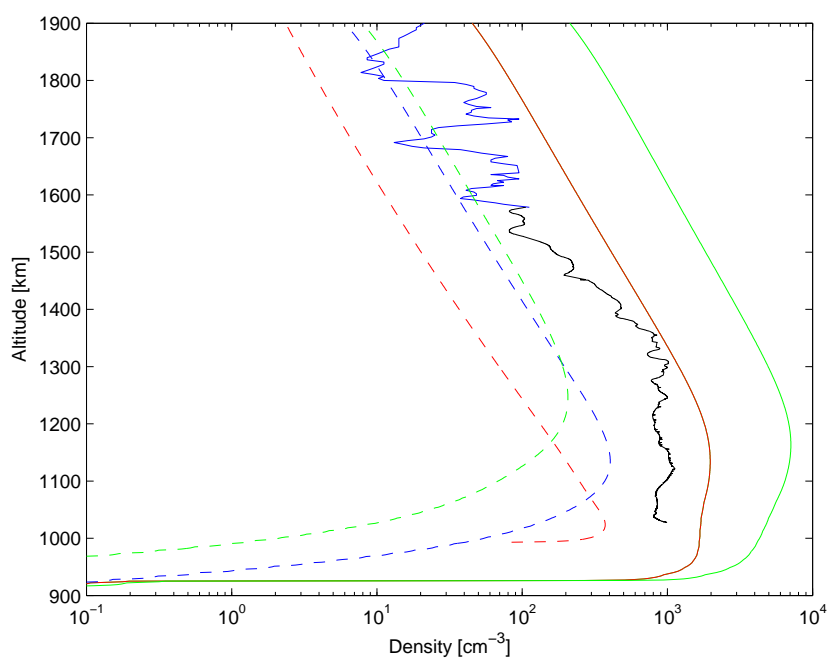

Fig. 11. The total electron density (green), total electron density with a flux reduced by ten (red) and densities for energy values of $30 \mathrm{eV}$ (green dashed), $150 \mathrm{eV}$ (blue dashed) and $500 \mathrm{eV}$ (red dashed) superposed on the measured electron density derived from the $f_{\mathrm{UH}}$ line (blue) and LP (black). The fluxes for the single energies are, respectively, $7.9 \times 10^{5}, 1.7 \times 10^{5}$ and $4.6 \times 10^{4} \mathrm{~cm}^{-2} \mathrm{~s}^{-1}$.

\section{Comparison with measurements}

The densities of the ions involved in the main reactions can be estimated through our model and the electron density is inferred from adding the ion densities, assuming quasineutrality of the plasma. By integrating the ionisation rate over all energies ranging from $10-1000 \mathrm{eV}$, we get a total ionisation rate valid for T5. Using this ionisation rate we may calculate the electron and ion densities for this flyby. Figure 11 shows the calculated total electron density superposed on the electron density measured by the LP. In addition, we show three single energies for comparison; 30, 150 and $500 \mathrm{eV}$ with corresponding fluxes of $7.9 \times 10^{5} \mathrm{~cm}^{-2} \mathrm{~s}^{-1}$, $1.7 \times 10^{5} \mathrm{~cm}^{-2} \mathrm{~s}^{-1}$ and $4.6 \times 10^{4} \mathrm{~cm}^{-2} \mathrm{~s}^{-1}$.

As can be seen in the figure, the total electron density is about an order of magnitude larger than expected. If we decrease the flux by a factor of ten we obtain results that are in agreement for the measured electron density (Fig. 11, red line) and for densities of the ion species (Fig. 12). It is noteworthy that an incident electron flux divided by a factor of ten provides a better agreement between the measured and the simulated total density.

There are at least five possible explanations to this discrepancy. 1) Large uncertainty in the density measurements. However, as can be seen in Fig. 3, the electron density measured by the LP matches the density inferred from the upper hybrid line. Also the INMS total ion densities agree well with the RPWS data (Cravens et al., 2005). Plasma density errors have been estimated to be less than $10 \%$ in the dense ionosphere. 2) Large uncertainty in the recombination coef-

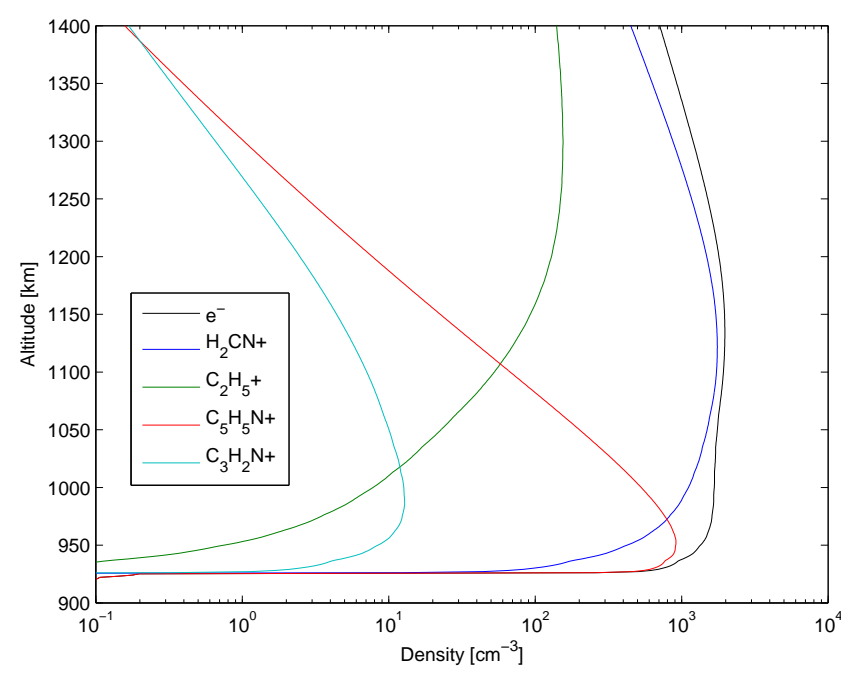

Fig. 12. Densities of the ion species and the total electron density for energies ranging from $10 \mathrm{eV}$ to $1000 \mathrm{eV}$ with incident fluxes reduced by a factor of ten.

ficient, $\alpha$, used in the model. The value used has been compared with the recombination coefficient from RPWS observations $\left(\alpha=q / n_{\mathrm{e}}^{2}\right)$ and good agreement between the two was found. 3) Rees' model might not be valid for use at Titan. However, the simplified approach we suggest has been validated by comparison with a comprehensive transport model, see Fig. 7. This transport model has in turn been validated against in situ observations and laboratory measurements at Earth. 4) The ionisation is significantly affected by the incident electron flux. ELS data is taken during upstream conditions approximately $20 \mathrm{~min}$ after $\mathrm{C} / \mathrm{A}$. The electron fluxes measured there may be different from the electron fluxes at C/A. In any case the presented ELS data in Fig. 10 show the characteristics of the differential number flux with energy, which affects the relative shape of the ionospheric profile. 5) The effect of the draping of the magnetic field may affect the estimation of the ionisation rate. Further investigations are needed to clarify the importance of each possible cause.

The model output for an incident electron flux divided by ten has been compared with INMS ion composition data by Cravens et al. (2006). At the exobase, located at approximately $1430 \mathrm{~km}$ (Waite et al., 2005), the electron, $\mathrm{H}_{2} \mathrm{CN}^{+}$ and $\mathrm{C}_{2} \mathrm{H}_{5}^{+}$densities are in qualitative agreement with the INMS data. Observations have shown that above the exobase transport of plasma becomes important in the forms of magnetospheric forcing and diffusion. Our model is therefore not valid in regions above that. The heavier ions are more abundant at lower altitudes, as expected. However, the $\mathrm{C}_{5} \mathrm{H}_{5} \mathrm{~N}^{+}$ ion is about a factor 10 more abundant in the model than in the INMS data. One possible explanation could be that $\mathrm{C}_{5} \mathrm{H}_{5} \mathrm{~N}^{+}$has an unexpected loss channel not included in the Keller model (Keller et al., 1998). 


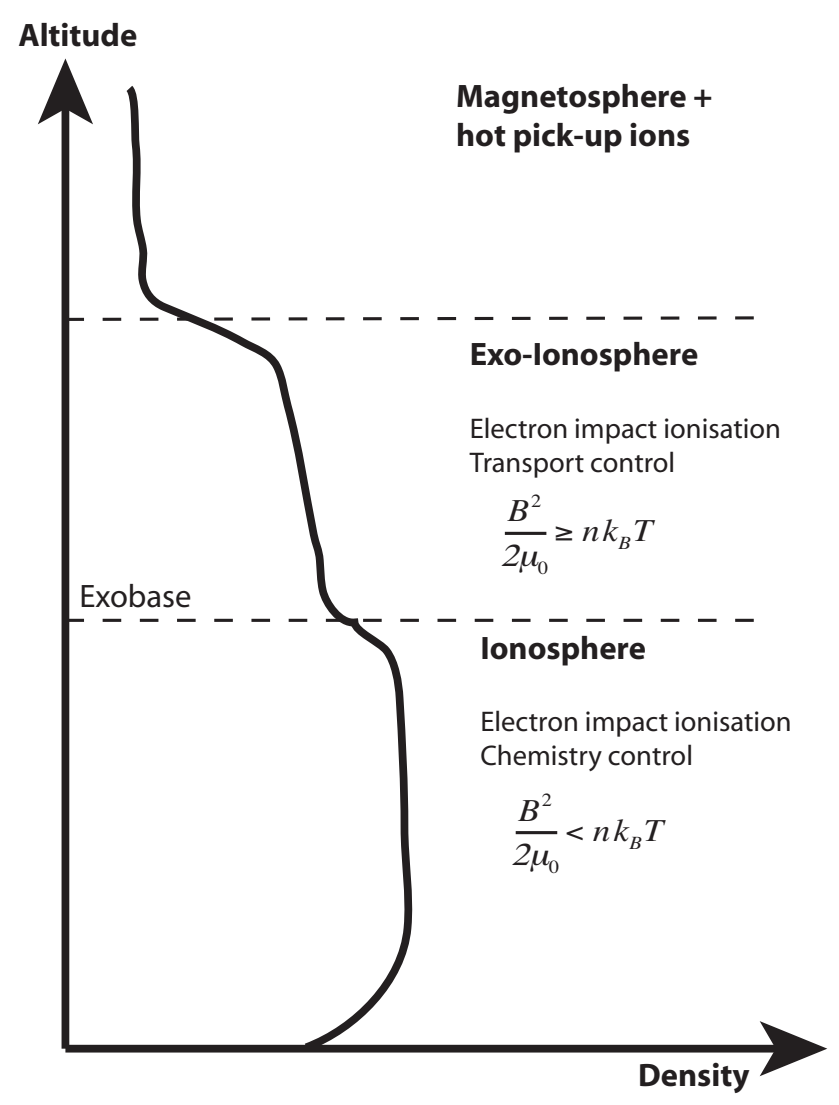

Fig. 13. Cartoon of Titan's ionosphere during eclipse conditions. The sharper boundary signatures are caused by the magnetospheric interaction with the cold and dense ionospheric plasma. During the T5 flyby the ionopause coincide with the exobase, which is not necessarily the case at other flybys. In the ionosphere the magnetic pressure can become comparable to the thermal pressure.

\section{Conclusions}

We have presented data from the sixth Cassini flyby of Ti$\tan$ (T5), showing that the magnetosphere of Saturn interacts strongly with the moon's ionosphere in several different and important aspects. We derived from RPWS observations that the most important region for the interaction is the exo-ionosphere. The exo-ionosphere begins near the exobase $(1430 \mathrm{~km})$ with plasma number densities near 100 $200 \mathrm{~cm}^{-3}$ and decreases exponentially outward with a scale height of $300 \pm 50 \mathrm{~km}$ to $2000-2500 \mathrm{~km}$ from Titan's surface, where after a sharp drop occurs to magnetospheric values (Fig. 13). During the Tb flyby this exo-ionospheric plasma reached $7000 \mathrm{~km}$ from the anti-Saturn side of Titan's surface (Wahlund et al., 2005), probably due to the large ion gyro-radii involved in the ion pick-up process. A dominant part of this exo-ionospheric plasma is "thermal" $\left(T_{\mathrm{e}}<5 \mathrm{eV}\right.$, $T_{\mathrm{i}}<5 \mathrm{eV}$ ). The magnetospheric magnetic pressure is larger than the thermal pressure in the exo-ionosphere, and the ef- fect of ion-neutral collisions should be small when considering the ion pick-up process. Recombination is slow, so transport dominates the structure of the exo-ionosphere.

In this case study we have shown, by the use of a simplified model, that magnetospheric electron impact ionisation alone can account for the observed ionospheric altitude profile for the outbound nightside flyby. Although chemistry dominates, the ionospheric structure can be modified by transport since the magnetic pressure at times is comparable to the thermal pressure down to the lowest observed altitude. This magnetospheric magnetic field is not efficiently shielded from the ionosphere, but rather diffuses slowly through and drapes around the ionosphere of Titan (Backes et al., 2005; Ness et al., 1982).

Acknowledgements. The Swedish National Space Board (SNSB) supports the RPWS LP instrument on board Cassini. The research at The University of Iowa was supported by NASA through contract 1279973 with the Jet Propulsion Laboratory. The authors acknowledge Activity N5 of Europlanet and would also like to thank the reviewers for their helpful comments which contributed to clarify and improve this article.

Topical Editor M. Pinnock thanks I. Sillanpää and two other anonymous referees for their help in evaluating this paper.

\section{References}

Backes, H., Neubauer, F. M., Dougherty, M. K., Achilleos, N., André, N., Arridge, C. S., Bertucci, C., Jones, G. H., Khurana, K. K., Russell, C. T., and Wennmacher, A.: Titan's Magnetic Field Signature During the First Cassini Encounter, Science, 308, 992-995, 2005.

Banaszkiewicz, M., Lara, L. M., Rodrigo, R., López-Moreno, J. J., and Molina-Cuberos, G. J.: A Coupled Model of Titan's Atmosphere and Ionosphere, Icarus, 147, 386-404, 2000.

Bertucci, C., Mazelle, C., Acuña, M. H., Russell, C. T., and Slavin, J. A.: Structure of the magnetic pileup boundary at Mars and Venus, J. Geophys. Res., 110, A01209, doi:10.1029/2004AJ010592, 2005.

Bird, M. K., Dutta-Roy, R., Asmar, S. W., and Rebold, T. A.: Detection of Titan's Ionosphere from Voyager 1 Radio Occultation Observations, Icarus, 130, 426-436, 1997.

Cravens, T. E., Robertson, I. P., Clark, J., Wahlund, J.-E., Waite, J. H., Ledvina, S. A., Niemann, H. B., Yelle, R. V., Kasprzak, W. T., Luhmann, J. G., McNutt, R. L., Ip, W.-H., De La Haye, V., Müller-Wodarg, I., Young, D. T., and Coates, A. J.: Titan's ionosphere: Model comparisons with Cassini Ta data, Geophys. Res. Lett., 32, L12108, doi:10.1029/2005GL023249, 2005.

Cravens, T. E., Robertson, I. P., Waite Jr., J. H., Yelle, R. V., Kasprzak, W. T., Keller, C. N., Ledvina, S. A., Niemann, H. B., Luhmann, J. G., McNutt, R. L., Ip, W.-H., De La Haye, V., Müller-Wodarg, I., Wahlund, J.-E., Anicich, V. G., and Vuitton, V.: Composition of Titan's ionosphere, Geophys. Res. Lett., 33, L07105, doi:10.1029/2005GL025575, 2006.

Fahleson, U., Fälthammar, C.-G. and Pedersen, A.: Ionospheric temperature and density measurements by means of spherical double probes, Planet. Space Sci., 22, 41-66, 1974. 
Galand, M., Lilensten, J., Toublanc, D., and Maurice, S.: The Ionosphere of Titan: Ideal Diurnal and Nocturnal Cases, Icarus, 140, 92-105, 1999.

Galand, M., Yelle, R. V., Coates, A. J., Backes, H., and Wahlund, J.E.: Electron temperature of Titan's sunlit ionosphere, Geophys. Res. Lett., 33, L21101, doi:10.1029/2006GL0274488, 2006.

Gurnett, D. A., Scarf, F. L., and Kurth, W. S.: The structure of Titan's wake from plasma wave observations, J. Geophys. Res., 87, 1395-1403, 1982.

Gurnett, D. A., Kurth, W. S., Kirchner, D. L., Hospodarsky, G. B., Averkamp, T. F., Zarka, P., Lecacheux, A., Manning, R., Roux, A., Canu, P., Cornilleau-Wehrlin, N., Galopeau, P., Meyer, A., Bostrom, R., Gustafsson, G., Wahlund, J.-E., Ahlen, L., Rucker, H. O., Ladreiter, H. P., Macher, W., Woolliscroft, L. J. C., Alleyne, H., Kaiser, M. L., Desch, M. D., Farrell, W. M., Harvey, C. C., Louarn, P., Kellogg, P. J., Goetz, K., and Pedersen, A.: The Radio and Plasma Wave Science Investigation, Space Sci. Rev., 114, 395-463, 2004.

Ip, W.-H.: Titan's upper ionosphere, Astrophys. J., 362, 354-363, 1990.

Keller, C. N., Anicich, V. G., and Cravens, T. E.: Model of Titan's ionosphere with detailed hydrocarbon ion chemistry, Planet. Space Sci., 46, 1157-1174, 1998.

Lummerzheim, D.: Electron Transport and Optical Emissions in the Aurora, Ph.D. Thesis, University of Alaska, Fairbanks, 1987.

Lummerzheim, D. and Lilensten, J.: Electron Transport and Energy Degradation in the Ionosphere: Evaluation of the Numerical Solution, Comparison with Laboratory Experiments and Auroral Observations, Ann. Geophys., 12, 1039-1051, 1994, http://www.ann-geophys.net/12/1039/1994/.

Lundin, R. and Barabash, S.: The wakes and magnetotails of Mars and Venus, Adv. Space Res., 33, 1945-1955, 2004.

Lundin, R., Barabash, S., Andersson, H., Holmström, M., Grigoriev, A., Yamauchi, M., Sauvaud, J.-A., Fedorov, A., Budnik, E., Thocaven, J.-J., Winningham, D., Frahm, R., Scherrer, J., Sharber, J., Asamura, K., Hayakawa, H., Coates, A., Linder, D. R., Curtis, C., Hsieh, K. C., Sandel, B. R., Grande, M., Carter, M., Reading, D. H., Koskinen, H., Kallio, E., Riihela, P., Schmidt, W., Säles, T., Kozyra, J., Krupp, N., Woch, J., Luhmann, J., McKenna-Lawler, S., Cerulli-Irelli, R., Orsini, S., Maggi, M., Mura, A., Milillo, A., Roelof, E., Williams, D., Livi, S., Brandt, P., Wurz, P., and Bochsler, P.: Solar Wind-Induced Atmospheric Erosion at Mars: First Results from ASPERA-3 on Mars Express, Science, 305, 1933-1936, 2004.

Molina-Cuberos, G. J., Lammer, H., Stumptner, W., Schwingenschuh, K., Rucker, H. O., López-Moreno, J. J., Rodrigo, R., and Tokano, T.: Ionospheric layer induced by meteoric ionization in Titan's atmosphere, Planet. Space Sci., 49, 143-153, 2001.

Mott-Smith, H. M. and Langmuir, I.: The theory of collectors in gaseous discharges, Phys. Rev., 28, 727-763, 1926.

Müller-Wodarg, I. C. F., Yelle, R. V., Mendillo, M. J., and Aylward, A. D.: On the global distribution of neutral gases in Titan's upper atmosphere and its effect on the thermal structure, J. Geophys. Res., 108, 1453, doi:10.1029/2003JA010054, 2003.
Ness, N. F., Acuna, M. H., and Behannon, K. W.: The induced magnetosphere of Titan, J. Geophys. Res., 87, 1369-1381, 1982.

Neubauer, F. M., Backes, H. Dougherty, M. K., Wennmacher, A., Russell, C. T., Coates, A., Young, D., Achilleos, N., André, N., Arridge, C. S., Bertucci, C., and Jones, G. H., Khurana, K. K., Knetter, T., Law, A., Lewis, G. R., and Saur, J.: Titan's near magnetotail from magnetic field and electron plasma observations and modeling: Cassini flybys TA, TB, and T3, J. Geophys. Res., 111, A10220, doi:10.1029/2006JA011676, 2006.

Niemann, H. B., Atreya, S. K., Bauer, S. J., Carignan, G. R., Demick, J. E., Frost, R. L., Gautier, D., Haberman, J. A., Harpold, D. N., Hunten, D. M., Israel, G., Lunine, J. I., Kasprzak, W. T., Owen, T. C., Paulkovich, M., Raulin, F., Raaen, E., and Way, S. H.: The abundances of constituents of Titan's atmosphere from the GCMS instrument on the Huygens probe, Nature, 438, 779-784, 2005.

Rees, M. H.: Physics and chemistry of the upper atmosphere. Cambridge University Press, Cambridge, 1963.

Toublanc, D., Parisot, J. P., Brillet, J., Gautier, D., Raulin, F., and McKay, C. P.: Photochemical modeling of Titan's atmosphere, Icarus, 113, 2-26, 1995.

Vignes, D., Mazelle, C., Rme, H., Acuña, M. H., Connerney, J. E. P., Lin, R. P., Mitchell, D. L., Cloutier, P., Crider, D. H., and Ness, N. F.: The solar wind interaction with Mars: Locations and shapes of the Bow Shock and the magnetic pile-up boundary from the observations of the MAG/ER experiment onboard Mars Global Surveyor, Geophys. Res. Lett, 27, 49-52, 2000.

Vuitton, V. and Yelle, R. V. and Anicich (Retired), V. G.: The Nitrogen Chemistry of Titan's Upper Atmosphere Revealed, Astrophys. Journal, 647, L175-L178, 2006.

Wahlund, J.-E., Boström, R., Gustafsson, G., Gurnett, D. A., Kurth, W. S., Pedersen, A., Averkamp, T. F., Hospodarsky, G. B., Persoon, A. M., Canu, P., Neubauer, F. M., Dougherty, M. K., Eriksson, A. I., Morooka, M. W., Gill, R., André, M., Eliasson, L., and Müller-Wodarg, I.: Cassini Measurements of Cold Plasma in the Ionosphere of Titan, Science, 308, 986-989, 2005.

Waite, J. H., Jr., J. H., Niemann, H., Yelle, R. V., Kasprzak, W. T., Cravens, T. E., Luhmann, J. G., McNutt, R. L., Ip, W.-H., Gell, D., De La Haye, V., Müller-Wodarg, I., Magee, B., Borggren, N., Ledvina, S., Fletcher, G., Walter, E., Miller, R., Scherer, S., Thorpe, R., Xu, J., Block, B., and Arnett, K.: Ion Neutral Mass Spectrometer Results from the First Flyby of Titan, Science, 308, 982-986, 2005.

Yelle, R. V.: Non-LTE models of Titan's upper atmosphere, Astrophys. J., 383, 380-400, 1991.

Yelle, R. V., Borggren, N., De La Haye, V., Kasprzak, W. T., Niemann, H. B., Müller-Wodarg, I., and Waite Jr., J. H.: The vertical structure of Titan's upper atmosphere from Cassini Ion Neutral Mass Spectrometer measurements, Icarus, 182, 567-576, 2006. 